\title{
Processed bottom ash for replacing fine aggregate in making high-volume fly ash concrete
}

\author{
Antoni $^{1, *}$, Aldi Vincent Sulistio $^{1}$, Samuel Wahjudi ${ }^{1}$, and Djwantoro Hardjito ${ }^{1}$ \\ ${ }^{1}$ Civil Engineering Department, Petra Christian University, Surabaya, Indonesia
}

\begin{abstract}
Bottom ash is a coal plant by-product that is abundant and underutilized. There is the potential use of bottom ash as a fine aggregate replacement in concrete mixtures; however, the problems of water absorption and uniformity of quality of the material need to be overcome first. In this study, bottom ash was treated by sieve separation and pounding to smaller particle size for use as a sand substitute. The physical and chemical characteristics of bottom ash were tested after treatment including water absorption, sieve analysis, and fineness modulus. Highvolume fly ash (HVFA) mortar specimens were made and the compressive strength and flowability test using bottom ash after treatment are compared with that of the sand specimen. Low water to cementitious ratio was used to ensure higher strength from the cementitious paste and superplasticizer demand was determined for each treatment. The result showed that bottom ash can be used as fine aggregate replacement material. Sieve separation of the bottom ash could produce $75 \%$ of the compressive strength compared with the control sand specimen, whereas pounded bottom ash could have up to $96 \%$ of the compressive strength of the control specimen. A 28-day compressive strength of $45 \mathrm{MPa}$ was achievable with $100 \%$ replacement of fine aggregate with bottom ash.
\end{abstract}

\section{Introduction}

The large amount of natural materials used in making concrete has been a concern in the construction industry. In some regions, natural sand has been irresponsibly mined, causing environmental damage. Concern about the large-volume usage of cement also has been raised due to the carbon released during cement production, making concrete a nonenvironmentally friendly material. A solution is needed to improve the sustainability of concrete from the perspective of raw materials and composition. Concrete developed, manufactured, and used in an environmentally friendly way is called "Green Concrete" [1] and efforts to reduce the use of cement by improving mix composition and replacing natural materials with recycled or waste materials are on-going, with further research needed.

\footnotetext{
*Corresponding author: antoni@petra.ac.id
} 
Fly ash and bottom ash are coal combustion waste materials from the burning process in power plants. For the use of bottom ash itself, there are still some difficulties such as irregular and rough bottom ash particle shapes [2,3]. In addition, using bottom ash in concrete mixtures reduces concrete strength, increases water absorption, and decreases density [4]. Bottom ash has a larger particle size than fly ash and a rough surface that can interlock easily, which lowers workability of the mixture. In addition, the porosity and water absorption are high, which increases the water requirement of the mixture [5]. Bottom ash can be treated by grinding and sieving to reduce the particle size to reduce water consumption and voids [6]; however, the grinding process requires a lot of energy and cost.

Fly ash material has been used in making high-volume fly ash (HVFA) concrete due to its beneficial effects. Small particle size and the rounded shape of the fly ash particles improve the workability of the paste mix, resulting in a decrease in the water requirement. HVFA concrete has at least $50 \%$ fly ash replacing cement, low water content $\left(\sim 130 \mathrm{~kg} / \mathrm{m}^{3}\right)$, and low water to cementitious ratio $(\mathrm{w} / \mathrm{cm}<0.4)[7,8]$. The use of high-volume fly ash in making concrete would reduce the use of cement as well as reduce the water use required for bottom ash mixtures [9,10].

The utilization of bottom ash in Indonesia is still rare due to its irregular, relatively large, and porous particles. In addition, environmental regulation lacks sufficient evidence regarding the use of this waste material. Much of the bottom ash generated by a power plant only accumulates in the ash pond and is then stacked in the fields. Therefore, this research aims to treat and utilize this abundant source of bottom ash as a replacement for sand in a mortar mixture. The HVFA mortar mixture aims to maximize the use of fly ash and bottom ash as well as minimize the use of cement. Early-age and long-term compressive strength and the workability of the mixture are evaluated to ensure a good performance of bottom ash as the aggregate replacement in concrete.

\section{Experimental methods}

\subsection{Materials}

The cementitious material used was Portland Pozzolan Cement (PPC) from PT. Semen Gresik and fly ash type C. The fly ash and bottom ash were from PT. Jawa Power at the Paiton power plant complex, East Java. The sand used was from a local quarry in Lumajang, East Java. The XRF test results from fly ash and bottom ash are presented in Table 1. The water used was demineralized water and the superplasticizer (SP) was a polycarboxylate ether-based type.

The bottom ash obtained was designated as raw bottom ash (RBA) and oven-dried before sieving into coarse bottom ash (CBA, with a particle size of $0-5 \mathrm{~mm}$, and fine bottom ash (FBA), with a particle size of $0-2.36 \mathrm{~mm}$. Bottom ash that did not pass the 5 $\mathrm{mm}$ sieve was pounded in $5 \mathrm{~min}$ increments until all particles passed the $5 \mathrm{~mm}$ sieve. These were designated as pounded bottom ash (PBA). The particle shapes of fly ash, sand, and bottom ash are illustrated in Figure 1.

Table 1. Oxide compositions for fly ash and bottom ash from the XRF test

\begin{tabular}{|c|c|c|c|c|c|c|c|c|c|c|c|c|}
\hline Oxide & $\mathrm{SiO}_{2}$ & $\mathrm{Al}_{2} \mathrm{O}_{3}$ & $\mathrm{Fe}_{2} \mathrm{O}_{3}$ & $\mathrm{CaO}$ & $\mathrm{MgO}$ & $\mathrm{SO}_{3}$ & $\mathrm{TiO}_{2}$ & $\mathrm{~K}_{2} \mathrm{O}$ & $\mathrm{P}_{2} \mathrm{O}_{5}$ & $\mathrm{MnO}_{2}$ & $\mathrm{Na}_{2} \mathrm{O}$ & $\mathrm{LOI}$ \\
\hline Fly ash & 34.29 & 16.62 & 15.38 & 18.18 & 7.52 & 1.63 & 0.73 & 1.35 & 0.25 & 0.17 & 2.97 & 0.36 \\
\hline Bottom ash & 34.39 & 10.02 & 18.41 & 21.16 & 9.7 & 0.66 & 0.65 & 0.9 & - & 0.22 & 0.24 & 3.54 \\
\hline
\end{tabular}




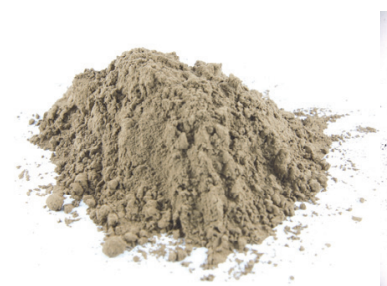

(a)

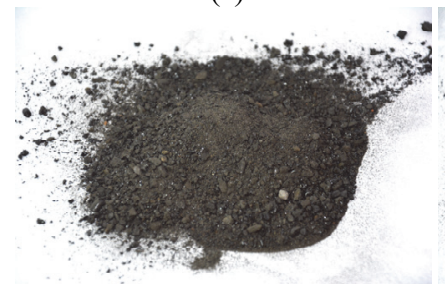

(d)

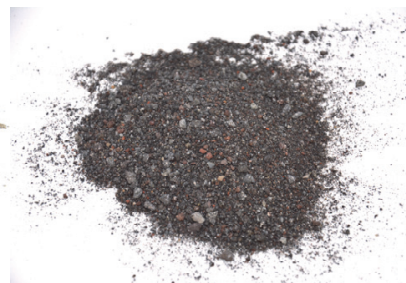

(b)

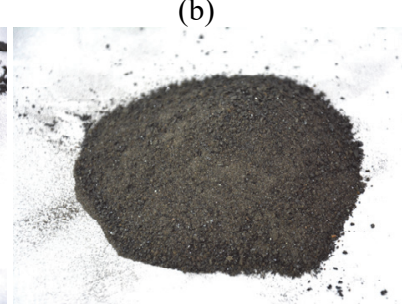

(e)

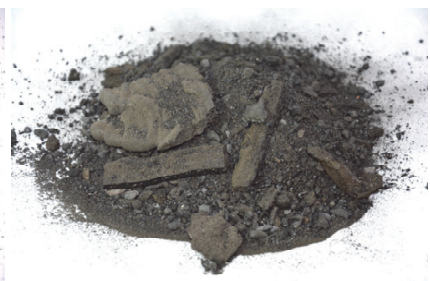

(c)

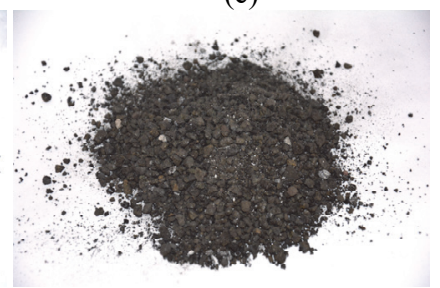

(f)

Fig. 1. Photographs of materials used in making the mortar specimens: (a) fly ash, (b) sand, (c) raw bottom ash, (d) coarse bottom ash passing $5 \mathrm{~mm}$ sieve, (e) fine bottom ash passing $2 \mathrm{~mm}$ sieve, and (f) pounded bottom ash.

\subsection{Mixture compositions and variables}

For the current experimental study, the water to cementitious ratio $(\mathrm{w} / \mathrm{cm})$ was fixed at 0.325 , and fly ash was used as cement replacement at level $50 \%$, by mass. Superplasticizer was prepared as required (SP demand) to achieve a flow diameter of $14 \pm 2 \mathrm{~cm}$. The SP demand is then calculated to the percentage of the cementitious mass. The aggregate to cementitious ratio was determined with the trial mixing with a target of a workable mixture and higher compressive strength. The HVFA mortar was then cast into specimens of $5 \mathrm{~cm} \times$ $5 \mathrm{~cm} \times 5 \mathrm{~cm}$. The compressive strength test of the mortar was conducted at $3,7,14,28$, and 56 days and 1 year, and three replications were conducted for each age testing.

The variable designations are as follow. "CTRL" was for the comparative specimen using Lumajang sand, with a prefix to indicate the bottom ash type: " $\mathrm{C}$ " for coarse, "F" for fine, and "P" for pounded. The numbers 100, 080, and 050 denote the mass percentages of the bottom ash replacing control sand. The suffixes $(-2,-2.5$, and -1.5$)$ show the aggregate to cementitious ratio, in mass.

\section{Results and discussions}

\subsection{Treatment of the bottom ash}

Different physical properties of the material were found for different sizes of bottom ash gradation. Water absorption from the saturated surface dry (SSD) condition and bulk volume are displayed in Figure 2(a). Coarse bottom ash had a higher absorption value compared with the fine bottom ash because the voids are reduced as the particles become finer. The bulk volumes of both coarse and fine bottom ash were about the same. Pounded bottom ash has a similar water absorption value with the coarse bottom ash as it has a similar maximum aggregate size, but with a higher bulk volume value, showing it has a higher compaction density. PBA has the largest bulk volume of $1706.67 \mathrm{~kg} / \mathrm{m}^{3}$, which is higher than that of sand $1629.33 \mathrm{~kg} / \mathrm{m}^{3}$. This is because the pounded bottom ash particles 
have good gradations such that they can pack together well and minimize the air space between particles.

The sieve analysis can be seen in Figure 2(b). It can be analyzed that the fine bottom ash (FBA) has a particle gradation that resembles Lumajang sand. The fineness modulus (FM) of the RBA is highest due to its much larger particle size. The results of the sieve grading analysis were used to calculate the FM of the material. The FM value for sand, CBA, FBA, PBA, and RBA were $2.454,2.633,1.991,3.323$, and 3.884, respectively.

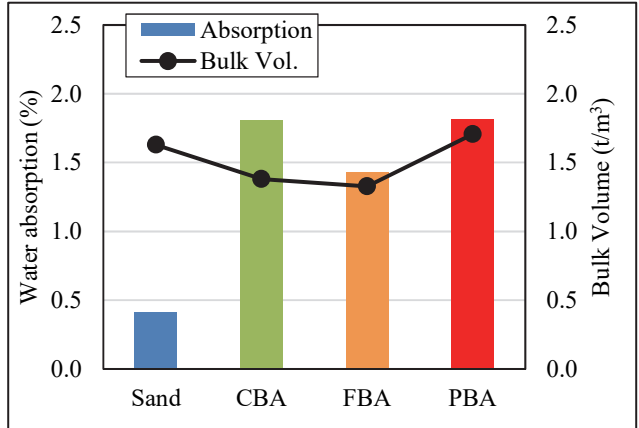

(a)

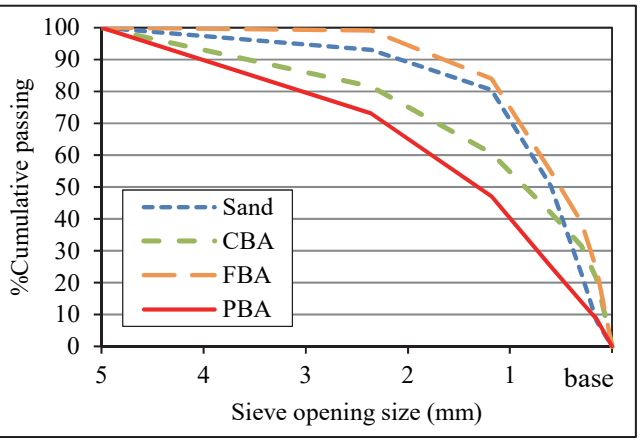

(b)

Fig. 2. Physical properties of the materials: (a) water absorption and the bulk density and (b) gradation of the fine aggregate.

\subsection{Behavior of fresh HVFA mortar}

Figure 3(a) shows the evaluations of flow diameter and SP demand for each mixed composition. The increased use of bottom ash generally leads to a decrease in flowability; thus, it is necessary to add SP to achieve the target flow diameter. A 50\% bottom ash replacement, no additional SP was needed; however, when replacing $80 \%$ and $100 \%$ sand with bottom ash, further SP was needed.

Mortar specimens with $100 \%$ FBA cannot be well made because the SP demand exceeds $2 \%$ and still does not reach target workability. Higher than 2\% SP was not explored further due to the detrimental effect of SP on the strength and setting time of the mixture as well as economic considerations. An adequate mixture could be made by reducing the ratio of FBA to cementitious to 1.5 by weight. This correlates well with the lower bulk volume that was previously measured.

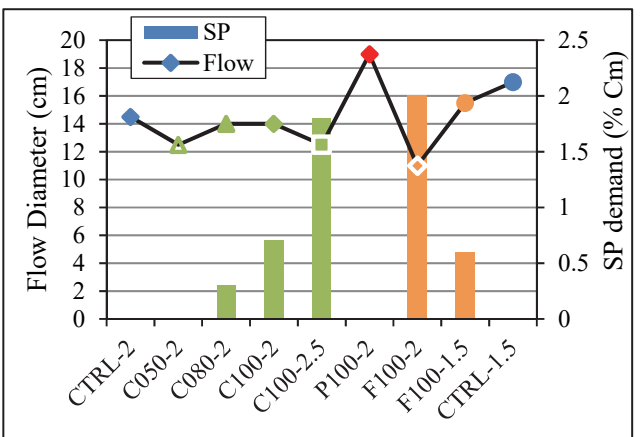

(a)

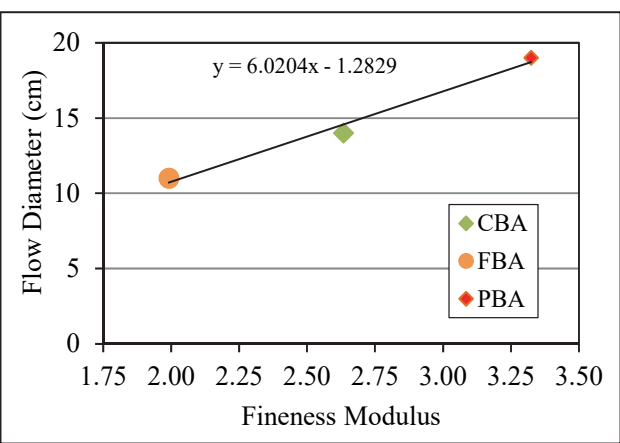

(b)

Fig. 3. (a) Measured flow diameter with superplasticizer demand and (b) relationship of flow diameter and the fineness modulus of the material. 
Fresh mortar with PBA has a higher flowability than the control sand due to higher bulk volume of the material. The highest flow diameter was achieved for a mixture using $100 \%$ PBA even without additional SP. High flowability corresponds with the high bulk volume value and also correlates with the fineness modulus of the aggregate as shown in Figure 3(b). From the trial, it was found also that higher flow diameter also produced specimens with a smooth surface.

\subsection{Properties of hardened HVFA mortar}

A compressive strength test was conducted on specimens after curing in water for the specified duration. Figure 4(a) shows the compressive strength of the entire mixture composition. The compressive strength graph shows a corresponding positive increase of strength with time. For the CBA series, C050-2, C080-2, and C100-2 showed that a higher sand replacement ratio a lower compressive strength was obtained. The 28-day strength of C100-2 was about $75 \%$ of the CTRL-2. The composition of C100-2.5 was made to maximize the use of bottom ash and had approximately the same strength with C100-2 at 28 days, but with a smaller diameter flow and more SP demand. However, when considering the later age strength, there was a low increment of strength for C100-2.5 specimen as opposed to still increasing of compressive strength for C100-2 because of the more cementitious material in the specimen.

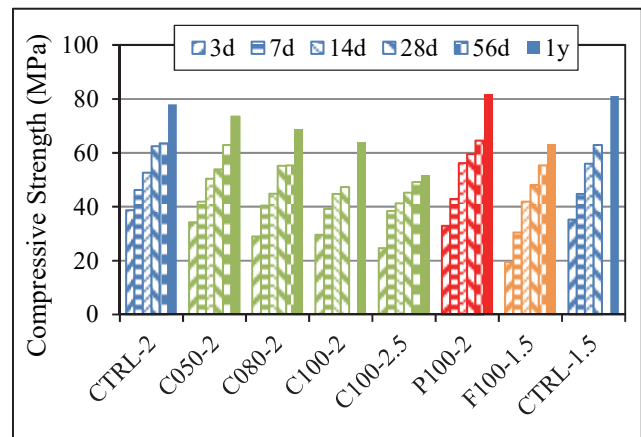

(a)

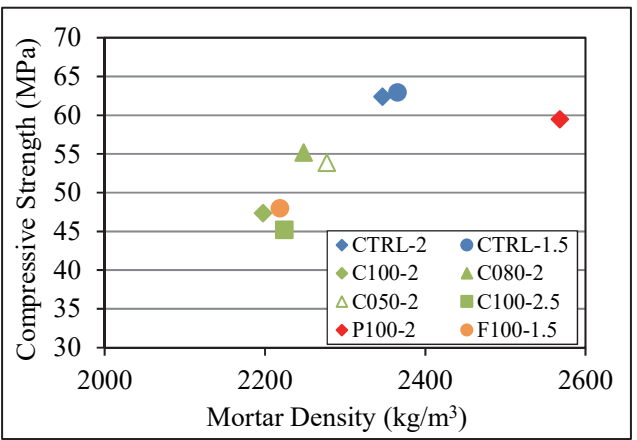

(b)

Fig. 4. (a) Compressive strength of the mortar up to 1 year of age and (b) relationship of mortar density and the 28-day compressive strength.

F100-1.5 mixture has lower strength compared with CTRL-1.5, showing that using finer bottom ash could reduce the water absorption of the material; however, it was more beneficial to use coarse bottom ash in the mixture. The compressive strength of the F1001.5 at 28 days was about $75 \%$ of the comparable mortar, CTRL-1.5. There was no compressive strength data for F100-2 due to workability and compactability problems.

Using PBA with coarser particle size, P100-2, had a high compressive strength, almost the same as CTRL-2 mortar. This was because the PBA material has a good gradation so that the bulk volume obtained was optimal.

Long-term compressive strength was conducted at up to one year of mortar age to check whether the bottom ash could have a detrimental reaction in the mortar. All of the specimens had higher strength than that of the younger age. Strength increase was more pronounced for specimens with a more cementitious proportion in the mixture, as the highvolume replacement of the cement with fly ash means a slower and longer reaction rate. The compressive strength of mortar is still increasing, even at later age.

Figure 4(b) shows the correlation of the 28-day compressive strength with the bulk density of each composition specimen. The tendency of higher bulk density to correlate 
well with the compressive strength was true in this case with the exception of the PBA specimen. It seems that P100-2 could have a higher bulk volume, but with a similar strength as the CTRL-2 specimen.

\section{Conclusions}

Bottom ash was treated by sieving and pounding to make HVFA mortar. From the study, the following conclusions were obtained.

1. The bulk volume of coarse bottom ash and fine bottom ash is lighter than sand, whereas the bulk volume of pounded bottom ash is $4.75 \%$ greater than sand due to a better gradation of the particles such that the gaps between them can be filled. This showed that the gradation of the particle could be one of the main factors in making a good concrete mixture.

2. Water absorption of the bottom ash can be reduced by crushing into a finer particle size; however, the absorption value was higher when compared with the control sand. The use of more bottom ash in the mixture would require higher superplasticizer dosage to obtain a workable mix when using a low water to cementitious ratio.

3. Replacement of fine aggregate using coarse and fine bottom ash at $100 \%$ ratio (C100-2 and F100-1.5) resulted in $75 \%$ of the control specimen's compressive strength. However, when combining the gradation of the coarse and fine particle (P100-2), the compressive strength obtained was similar to the control specimen. This is due to good particle gradation, which increases the bulk density and, thereby, increases its compressive strength.

4. There is a reduction of fresh mortar flowability with the addition of coarse and fine bottom ash as indicated by the increase of superplasticizer demand. However, when a good gradation of the bottom ash particle was attained, the workability was comparable with the control sand. Therefore, the gradation of particles needs to be controlled to achieve a good workable and strong HVFA mortar.

5. Long-term concrete strength up to one year using bottom ash as the fine aggregate replacement was increased, indicating that there was no long-term detrimental effect on the usage of bottom ash in the concrete mixture.

Acknowledgment to PT. Jawa Power for providing the fly ash and bottom ash for the experimental study under MOU number 002/MoU/FTSP/UKP/2015-YTLJT/LTR/2015/00734 and The Ministry of Research, Technology and Higher Education, Indonesia for providing financial support.

\section{References}

1. T. Proske, S. Hainer, M. Rezvani \& C. Graubner, Cem. Concr. Res, 51 38-46 (2013)

2. H. K. Kim. \& H. K. Lee, Constr Build Mater 25(2), 1115-1122 (2011)

3. M. Singh \& R. Siddique, J Clean Prod 112, 620-630 (2015)

4. H. K. Kim. \& H. K. Lee, J Mater Civil Eng, 25(May), 662-665. (2013)

5. L.B. Andrade, J.C. Rocha \& M Cheriaf, Constr Build Mater 23, 609-614 (2009)

6. H. K. Kim, Constr Build Mater 91, 57-64. (2015)

7. M. Reiner \& K. Rens, Pract Period Struct Des Construct, 11, 58-64. (2006)

8. S. V. Deo, Road Mater Pavement. 16(3), 707-715. (2015)

9. A. A. Ramezanianpour, Cement Replacement Materials (Springer, Berlin, 2014)

10. Antoni ,V. Satrya \& D. Hardjito, Civ Eng Dim, 17(1), 38-43 (2015) 